\title{
Pond conservation: from science to practice
}

\author{
Beat Oertli · Régis Céréghino · Andrew Hull • \\ Rosa Miracle
}

Published online: 5 August 2009

(C) Springer Science+Business Media B.V. 2009

\begin{abstract}
In Europe, ponds are an exceptionally numerous and widely distributed landscape feature forming a major part of the continental freshwater resource and contributing significantly to freshwater biodiversity conservation. This has been reflected by a growing scientific concern over the first few years of the twenty-first century and is evidenced by an increasing number of academic publications on pond related topics, particularly those relating to biodiversity. It is essential, however, that this expanding scientific knowledge is widely disseminated to those involved with pond management and is then rapidly translated into action. Inevitably, the task of transferring science to practice remains a significant
\end{abstract}

Guest editors: B. Oertli, R. Céréghino, A. Hull \& R. Miracle Pond Conservation: From Science to Practice. 3rd Conference of the European Pond Conservation Network, Valencia, Spain, 14-16 May 2008

B. Oertli $(\square)$

University of Applied Sciences Western Switzerland, hepia Lullier, 150 route de Presinge, 1254 Jussy-Geneva, Switzerland

e-mail: beat.oertli@hesge.ch

R. Céréghino

University of Toulouse, Toulouse, France

A. Hull

Liverpool John Moores University, Liverpool, UK

R. Miracle

University of Valencia, Valencia, Spain challenge. As a first step towards meeting this challenge the European Pond Conservation Network (EPCN), at its biennial meeting in 2008 in Valencia (Spain), made this the main theme of the conference together with two special workshops further encouraging exchanges between scientists, practitioners and policy makers. The papers selected for this special issue of Hydrobiologia (from over 120 communications presented) are all from the conference. They represent a diverse collection of themes from across the continent and North Africa and present new and original insights into topics as wide ranging as: pond biodiversity; human disturbance; landscape ecology; ecological assessment and monitoring; practical management measures; ecological restoration; hydrology and climate change; invasive species and threatened species. In all cases, the papers demonstrate an overriding need for the development of a tight link between scientific knowledge and management. Furthermore, scientific advances have to be beneficial for on the ground management and, vitally, have to be disseminated, communicated and implemented into local, national and international policy. As such, national and international networks (such as the EPCN) have a central role to play and have to develop a robust information and communication strategy which will enable the dissemination of best practice materials and advice across the continent and beyond. The work contained in this volume represents a step in the right direction and will help to ensure that ponds remain a characteristic and highly 
visible feature of the European landscape in the twenty-first century.

Keywords Biodiversity conservation Management · Ponds - Small waterbodies .

Temporary pools $\cdot$ Europe

\section{A network of stakeholders for a neglected freshwater resource}

The management and conservation of freshwater resources has traditionally focussed upon running water and larger waterbodies. In comparison small waterbodies, such as ponds, have long been overlooked. Recently, however, there has been a growing realization that these small wetland patches are important not only for biodiversity but also for a range of socio-economic activities linked to them. Ponds, of course, are very numerous and worldwide there are hundreds of millions (Downing et al., 2006). Their small size $\left(1 \mathrm{~m}^{2}-5 \mathrm{ha}\right)$ coupled with their great abundance has meant that these small waterbodies have a critical role to play in the global carbon cycle, as collectively they probably trap significantly more carbon than the worlds oceans (Downing et al., 2008). Furthermore, together, they host a high and unique biodiversity, particularly significant at the regional scale, when compared to other freshwater systems (Williams et al., 2003).

In Europe ponds form a significant part of the continental freshwater resource. In order to address this issue, a collaborative workshop was held in Geneva (Switzerland) in 2004 (Oertli et al., 2005a) resulting in the launch of an international forum-the "European Pond Conservation Network" (EPCN; www.europeanponds.org). The EPCN was established with the principal aim of coordinating research, policy and management through the promotion of awareness, understanding and conservation of ponds in a changing European landscape. Since the first workshop the network has grown steadily and successfully and has held an international conference every 2 years since the original meeting in Geneva. The second EPCN conference took place in Toulouse (France) in 2006 (Céréghino et al., 2008) and a third in Valencia (Spain) in 2008. This most recent EPCN conference was organised by the Government of the Valencian Region (Conselleria de Medi Ambient, Aigua Urbanisme i
Habitatge of the Generalitat Valenciana). Its success can be measured by the 130 delegates attending from 25 countries (Austria, Belgium, Czech Republic, Denmark, Estonia, France, Germany, Greece, Hungary, Iceland, Ireland, Italy, Mexico, Morocco, Netherlands, Poland, Portugal, Slovakia, Slovenia, Spain, Sweden, Switzerland, Tunisia, UK, USA). The participants included scientists attached to universities and wetland research agencies together with a variety of other 'pond stakeholders' including field managers, local authority representatives, politicians and conservation NGO's. A total of 123 communications were presented, 38 as oral presentations and 85 as posters (which can be downloaded from http://campus.hesge. ch/epcn/posters_valencia08.asp). At the Valencia conference an important milestone was delivered with the publication of the "Pond Manifesto" (EPCN (European Pond Conservation Network), 2008). This vital document, drafted and appended during the first two conferences in 2004 and 2006 (EPCN (European Pond Conservation Network), 2007), presents the case for conserving European ponds and provides an outline strategy for much needed conservation action across and beyond the continent.

This special issue of Hydrobiologia represents a selection of the communications presented in Valencia and includes a broad range of topics covering research activity across Europe and North Africa.

\section{A growing scientific interest for ponds and their biodiversity?}

It has become increasingly clear that research activity focussing upon ponds and other small water bodies has risen significantly over the past few years. The number of publications in peer-reviewed journals is a good indicator of this progress and taking the number of publications addressing the topic "pond" into consideration (in the ISI Web of Knowledge database), the trend between 1991 and 2008 illustrates two defined periods before and after 2001 (Fig. 1). At the world level, the number of indexed publications is higher after 2001 than before (about 10\% higher), but this is even more marked at the European level (about $40 \%$ higher).

Taking the two keywords "pond" and "biodiversity" into consideration, the trend since 1991 shows a different pattern, with a continuous and very sharp 


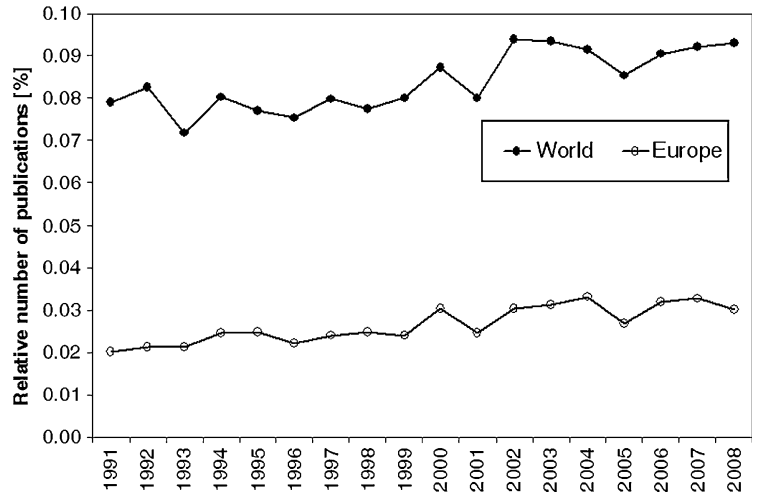

Fig. 1 Temporal dynamic between 1991 and 2008 of the number of "pond" publications indexed in ISI Web of Knowledge database (upper line world, underline Europe). Both trends underline higher proportions of "pond" publications subsequent to 2001. The number of "pond" publications is expressed in \% (ratio on the total number of publications indexed), to avoid a possible bias linked to the continuous increase in the total number of publication indexed in the database. The search was realised on ISI Web of KnowledgeScience Citation Index Expanded (SCI-EXPANDED)—Topic "pond" or "ponds"

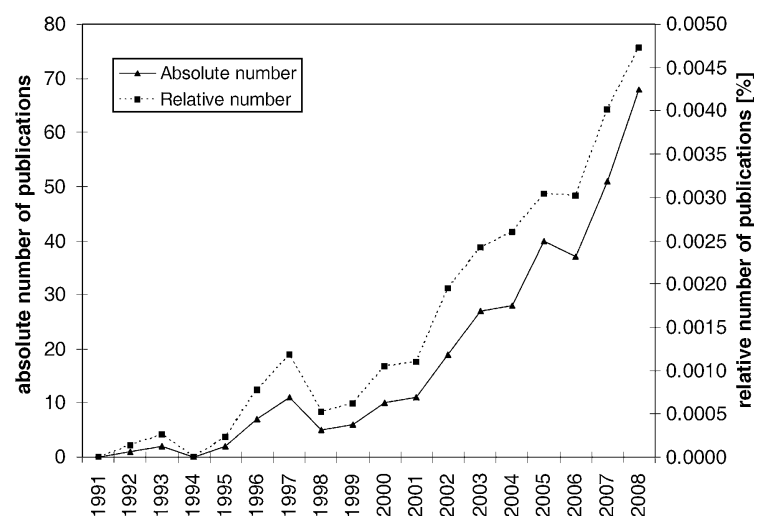

Fig. 2 Increase in the number of peer-reviewed publications addressing both topics "pond" and "biodiversity" from 1991 to 2008. The publications taken into consideration are those indexed in ISI Web of Knowledge database (keywords "pond" or "ponds" and "biodiversity"). Relative values expressed in $\%$ (ratio to the total number of publications indexed each year) are also presented; they evidence here a same increasing trend

increase (Fig. 2), even sharper since the EPCN was launched in 2004. In 2008, about 70 publications were indexed-seven times more than in 2000. The greatest part of this increase relates to a growing interest in biodiversity. Indeed, this trend can also be observed for other types of freshwater systems including rivers, streams and lakes (Fig. 3). Despite

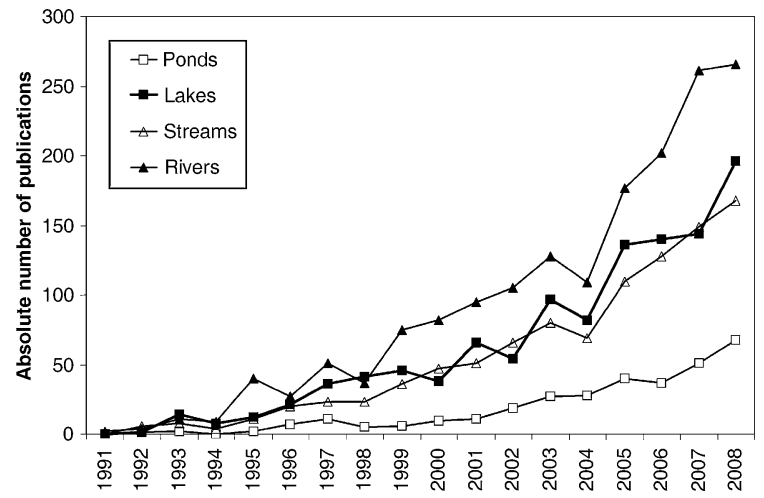

Fig. 3 Increase in the number of peer-reviewed publications addressing together the topic "Biodiversity" and one of the four types of freshwater systems ("ponds" or "lakes" or "rivers" or "streams") from 1991 to 2008. The publications taken into consideration are those indexed in ISI Web of Knowledge database. The relative values (ratio to total number of publications indexed) present the same trends and are therefore not presented here

these encouraging trends, there still remains a much greater interest for lakes and running waters and, of the four freshwater types, the proportion of pond publications still remains under $10 \%$ during the period, from 1991 to 2008 . This stresses the necessity to undertake more pond research, especially if we accept the high value of ponds in the conservation of global freshwater biodiversity.

Inevitably, the increase in publications dealing with biodiversity is a consequence of the Rio Conference of 1992 and of the recognition that this topic is central to nature conservation. Nevertheless, it is depressing that scientific literature on freshwater biodiversity only increased sharply after 200210 years after Rio Conference-and underlines a poor relationship between policy and research.

Nevertheless by 2008, a large number of researchers are actively involved in investigating "pond biodiversity", as the Valencia conference illustrated. This underlines also an increasing size of the body of researchers. Accordingly, the EPCN has a critical role to play in facilitating and enhancing interaction and exchange between universities and research agencies and moving towards joint working in similar situations in different European countries. Another vital step to be undertaken by the EPCN is the communication of research outputs to all stakeholders and, principally, land owners, land managers and policy makers. The broad dissemination of information 
remains a key objective of the EPCN and needs to be undertaken at the local, national and international level.

\section{Linking scientific knowledge and management}

An encouraging development at the third EPCN conference in Valencia was the presence of representatives from a variety of stakeholder groups including researchers, field managers and local authorities. This diversity is also reflected by the communications presented which included many excellent case studies on pond management and biodiversity and this scientific exchange between scientist and managers provided a unique opportunity for serious networking. In order to enhance this process, a special workshop was dedicated to this topic-Linking pond management to scientific knowledge-with the aim of creating a better link between scientists and practitioners, and to improve the evidence base for pond conservation and management. Clearly, much knowledge on pond management is still held by practitioners working "on the ground" and in many cases this never reaches publication and therefore unavailable for others to learn from. Conversely, there is relatively little scientific research on pond management, or monitoring to assess the result of management activities. Clearly, both scientists and practitioners would both benefit from sharing best practice experiences and knowledge and one of the main themes of the workshop, was to discuss the key issues to develop pond management practices based on a sound scientific basis. One of the main questions considered was: "How is it possible to improve the flow of information between management and research ?". Importantly, managers are also aware of good (and bad !) management practices and, all too often, these success stories are seldom highlighted. In order to tackle this issue a second workshop was held-Pond management success stories - to address positive and innovative approaches from across the continent. It was agreed that success stories need to be more widely disseminated to both managers, the scientific community and all other stakeholders. It was acknowledged that peer-reviewed journals play only a limited role here, only occasionally publishing such case studies (but see exceptions as Williams et al.,
2008 or Rannap et al., 2009). Furthermore, peerreviewed literature is often not read by end-users, partly because they don't have access to them, or because they do not read the English language. Inevitably, good practices and success stories are often published only in local journals, remaining for the most part in the grey literature. In future, it was felt that the web could play a central role in providing a platform for such case studies, centralising all type of literature and it was decided that this should be another key objective for the EPCN and the development of its website.

\section{Special issue content}

The papers selected for this special issue cover a variety of themes from different parts of Europe and North Africa, and in all cases demonstrate the link between scientific knowledge and management. The themes included in this volume are reflected by keywords including: biodiversity, human disturbance, landscape ecology, ecological assessment, practical management measures, ecological restoration, climate changes, invasive species, threatened species and monitoring.

Basic knowledge on pond biology and ecology is still full of gaps, and even areas regarding fauna and flora assemblages remain poorly understood. Pond biodiversity is particularly important at the regional scale (Oertli et al., 2002; Williams et al., 2003; Angélibert et al., 2006), but such regional studies are still scarce and there is an urgent need for studies from other parts of Europe. This is particularly important for regions where some of the most seriously threatened pond types can still be found (e.g. Mediterranean temporary pools and turloughs in the western extremities of the British Isles). PintoCruz et al. (2009) demonstrate in this volume that knowledge on plant assemblages associated with Mediterranean temporary ponds (European community priority habitat Number 3170 ) is an important determinant for regional biodiversity conservation. In the light of these findings, similar investigation needs to be undertaken on other pond types, including newly created ponds designed for novel uses in the twenty-first century.

Over the past century, ponds have been faced with a great variety of human disturbance and no more 
so than during the past 50 years. Even today, and despite our greater knowledge, pond filling, water pollution and eutrophication continue to be unchecked in many parts of Europe and this presents perhaps one of the greatest challenges to managers who must learn to deal effectively with these deep rooted problems.

Disturbances also often occur at the local scale and here experimental approaches conducted directly on ponds can be very useful and can give accurate information to the manager for tackling the identified problem. For example Amami et al. (2009) and Sahib et al. (2009) considered the effect of small scale disturbances in a series of Mediterranean temporary pools (simulating that caused by herbivorous mammals). Results showed that the richness of plant communities was not affected by this disturbance (Sahib et al., 2009). Furthermore, the recovery from such disturbance was rapid and, after 2 years, the species composition of the vegetation in disturbed plots was similar to that of the control plots (Amami et al., 2009). These results do not necessarily mean that disturbance by herbivores, especially during the plants' growing season, will not have a significant impact on the vegetation and its richness, but rather that its impact can be modulated.

Landscape ecology is particularly relevant when managing small waterbodies. Ponds should never be considered in isolation and the growing realisation that pond landscapes-once common in many parts of Europe-are now seriously threatened, has serious implications for biodiversity. The acknowledgement of climate change and the northward movement of many species means that ponds have a vital role to play as stepping stones through the landscape. In the Landscape Protected Areas (LPA) of southern Estonia, the creation of several hundred ponds for the management of amphibian populations demonstrates how effectively conservation measures can be put in place (Rannap et al., 2009). The significance of conserving biodiversity at the regional scale was also demonstrated by Triest and Sierens (2009) who emphasize the role of regional pond habitat diversity for the preservation of Ruppia taxa and their unique haplotype diversity in extreme saline habitats. Ponds also provide a stepping stone for freshwater biodiversity linked to larger waterbodies providing a resting place for birds and mammals (e.g. beaver, otter) (e.g. Santoul et al., 2009).
Ecological assessment is a topic of applied research which is particularly useful for managers but exchanges between researchers and practitioner need to focus on the development of tools that respond both to international, national or regional policy (nature conservation and freshwater management) and also to the needs of practitioner. Such standardised tools have been developed for running waters or lakes, but are still scarce for ponds. Some tools have now been developed in selected regions of Europe (e.g. Biggs et al., 2000; Boix et al., 2005; Chovanec et al., 2005; Oertli et al., 2005b; Solimini et al., 2008; Indermuehle et al., 2009; Trigal et al., 2009). In the present issue, Della Bella \& Mancini (2009) investigate how macroinvertebrates and diatoms communities in Italian permanent ponds can be useful bioindicators (taxa and metrics) to evaluate the effect of human impacts (water pollution or habitat alteration). In another study conducted in Switzerland, Sager \& Lachavanne (2009) propose a method based on the aquatic plant communities to assess easily and to monitor the trophic state of ponds.

Pond managers also want scientific support for practical management measures. This is particularly important in relation to threatened species, especially those confined mainly to ponds. Experimental research brings an important contribution to the understanding of the ecology of species and to the response to management practices. Rannap et al. (2009) demonstrate how new ponds created within an existing network of several hundreds of ponds enhances the number of breeding sites of two threatened amphibian species-the crested newt (Triturus cristatus Laur.) and the common spadefoot toad (Pelobates fuscus Wagler). Research experiments conducted in the laboratory are also invaluable. Rhazi et al. (2009b) tested the competition between two plant species - a locally invasive clonal species (Bolboschoenus maritimus) and a rare threatened quillwort (Isoetes setacea)-typical in the Mediterranean temporary pools of southern France. They demonstrate that although the threatened species is eventually excluded by the invasive species, the threatened species can nevertheless survive in pioneer situations-practical advice that will be passed on to managers.

Management is often also directed to ecological restoration. Peretyatko et al. (2009) present an example conducted in ponds from Belgium: the 
effects of biomanipulation (fish removal) was assessed on different compartments of pond ecosystems (phytoplankton, zooplankton, submerged vegetation and nutrients). The results clearly indicated that such management intervention can be used, at least, for the short-term restoration of ecological water quality. The most drastic restoration measure is the creation of a new pond. This measure is often undertaken locally to compensate for the drastic loss in pond number at the regional scale. The creation of a new pond is also often much more appropriate (and less expensive) than the attempt of restoring a given degraded pond. Managers are aware of good practices and also of the benefits of such a management measure. Ruhí et al. (2009) present an assessment of the impact on macrofauna of the creation of new ponds in Catalonia (NE Iberian Peninsula). This work confirmed that the colonisation process is very rapid and $50 \%$ of the species found in the study were already captured 1-2 months after flooding. However, more time is needed for the establishment of specialized populations and in particular those linked to aquatic plants. Another particularly successful example of creating a new pond complex was detailed by Williams et al. (2008).

What is the future for ponds in the European landscape of the twenty-first century ? Local managers are at the forefront and are the first to be faced with these new challenges which have been brought about by an ever changing landscape, land use and local practice. Scientists have therefore to work closely not only with natural ponds, but also with the many hundreds of thousands of ponds created by human intervention across Europe during the past few centuries. Importantly, the era of pond digging is still prevalent and new demands for water storage, flood defence and biodiversity conservation are generating new pond types and, increasingly, managers want information about these new habitats and how they can be managed to maximise their utility. Even if these new ponds never replace vanishing pond types, they can provide some contribution for conserving regional freshwater biodiversity. Artificial ponds, a priori considered to have little or no interest, can reveal surprising results. Highway stormwater retention ponds have already been presented as biodiversity islands (Scher et al., 2004). Becerra-Jurado et al. (2009) in this volume highlighted the potential contribution of constructed ponds used for wastewater treatment to the landscape biodiversity in Ireland. Gravel pits constitute another example of an important artificial pond type. For example in an urban landscape in South-western France, a set of gravel pits captured more than half of the regional species pool of aquatic birds (Santoul et al., 2009). Urban or semiurban ponds also play also a crucial role in enhancing the vital link between people and nature. Even urban ponds have to be managed, even if biodiversity remains often a secondary objective to esthetics or human health and welfare. Peretyatko et al. (2009) present a successful management intervention focussed on the prevention of noxious cyanobacterial bloom formation in ponds in the heart of Brussels.

Ponds in the twenty-first century will also have to face global challenges, especially climate change. Recently, completed models of temperature increases in Alpine ponds predict drastic changes in species assemblages and richness (Rosset et al., 2008). Changes in the hydrology will also be a key factor to investigate and Florencio et al. (2009) demonstrate in this volume how hydroperiod can have a decisive influence on the composition of macroinvertebrate assemblages in Mediterranean temporary ponds. This was also observed during first years of macrofauna colonisation of new excavated ponds (Ruhí et al., 2009). The same evidence came also from studies of aquatic plants from these Mediterranean temporary ponds: hydrology appears to be the primordial factor that structures and selects the species of a community (Sahib et al., 2009; Rhazi et al., 2009a); the hydrology modifies any disturbance effects and influences competition intensity through its impact on primary production. The expected reduction of humid years and of rainfall globally may lead to a decrease in the probability of survival of populations of characteristic pool species (Rhazi et al., 2009a). Such data will be particularly useful in the future, because we expect drastic changes in hydroperiod length. For example, a hydroperiod decrease of more than 52 days is predicted for Lake Kourna, a Mediterranean Temporary Pond from Crete (predictions with IPCC B2 and A2 climate scenarios) (Dimitriou et al., 2009). Investigations on the effect of the length of the hydroperiod have not only focussed upon Mediterranean waterbodies-in the future, we have also to consider the effect of 
changing hydrology on permanent ponds, which in turn can become temporary or can benefit (or suffer) from a large drawdown zone.

Globally, invasive species will be an increasing threat for biodiversity in the twenty-first century, due to a sharp rise in the geographical movement of species. This is particularly true for freshwater ecosystems (e.g. Ricciardi, 2006), including ponds. Aquatic plants, snails, turtles and fish species are moved around the world by aquarium hobbyists; many exotic, and potentially invasive species, often finish in a garden pond or in a natural pond close to human settlement. Spreading through other processes and of other taxa is also observed; for example Rodríguez-Pérez et al. (2009) have monitored the colonisation of the North American aquatic bug Trichocorixa verticalis verticalis (Hemiptera: Corixidae) in the wetlands of Doñana (southern Spain).

Long-term monitoring can provide particularly rich information, especially in the context of global change and many protected areas have now set up systems to monitor their biodiversity. In a few cases, this also includes the monitoring of pond networks, but to date this remains rare. With their small size and their relatively simple community structure, ponds provide an ideal sentry and early warning system (De Meester et al., 2005). To this effect in 2002, the Swiss National Park has begun a long-term monitoring programme of freshwater systems, including about 30 alpine ponds (Robinson \& Oertli, 2009). Fahd et al. (2009) present in this volume a four-decade record (1964-2007) of the Copepods and Branchiopods associated with 50 temporary ponds in the Doñana National Park (SW Spain) and underline the usefulness of such long-term monitoring. Shorter time span can also already bring useful results, as demonstrated here by a 10-years continuous monitoring in a Mediterranean temporary pool facing fluctuating hydrology (Rhazi et al., 2009a).

\section{Conclusion}

In the early twenty-first century there is a growing interest for ponds, and this is clearly reflected by an increasing scientific activity, especially on the topic of biodiversity. It is vital to link this research with the needs expressed by managers, practitioners and policy makers. Furthermore, these scientific advances have to be beneficial for "on the ground" management and have to be disseminated, communicated and implemented into local, national and international policy. National and international networks (such as the EPCN) have a central role to play and have to develop a robust information and communication strategy which is disseminated across the continent and beyond. Conferences and workshops are unique occasions and help to disseminate knowledge and information and in this light the fourth EPCN conference is already scheduled for Berlin in June 2010. After the Valencia conference in 2008, which largely focussed on Mediterranean waterbodies, the gathering in Berlin will provide an opportunity to further promote pond conservation in northern Europe.

Acknowledgements We are very grateful to the "Valencia team" for the organisation of a very successful and useful meeting. In particular; special thanks goes to Ignacio Lacomba, Vicente Sancho, Benjamí Perez and all the other anonymous helpers who contributed to the excellent organisation and hospitality in their beautiful city. Thanks also for their supports to the Life-Nature project "Restoration of priority habitats for amphibians" (LIFE05/NAT/E/00060) and to the Conselleria de Medi Ambient, Aigua Urbanisme i Habitatge of the Generalitat Valenciana. We would also like to acknowledge the support from the MAVA Foundation for the organisation of the two workshops "Pond management success stories" and "Linking pond management to scientific knowledge". We would also like to thank Audrey Greenman for undertaking the data analysis for Figs. 1, 2 and 3 and, finally, thanks to the 60 reviewers who provided helpful comments on the manuscripts submitted to this special issue.

\section{References}

Amami, B., L. Rhazi, S. Bouahim, M. Rhazi \& P. Grillas, 2009. Vegetation recolonization of a Mediterranean temporary pool in Morocco following small scale experimental disturbance. Hydrobiologia (this issue).

Angélibert, S., N. Indermuehle, D. Luchier, B. Oertli \& J. Perfetta, 2006. Where hides the aquatic biodiversity in the Canton of Geneva (Switzerland)? Archives des Sciences 59: 225-234.

Becerra Jurado, G., M. Callanan, M. Gioria, J.-R. Baars, R. Harrington \& M. Kelly-Quinn, 2009. Aquatic macroinvertebrate diversity of natural and wastewater treatment ponds: community structure and driving environmental factors. Hydrobiologia (this issue).

Biggs, J., P. Williams, M. Whitfield, G. Fox \& P. Nicolet, 2000. Biological techniques of still water quality assessment: phase 3. Method development. Environment Agency, Bristol. 
Boix, D., S. Gascon, J. Sala, M. Martinoy, J. Gifre \& X. D. Quintana, 2005. A new index of water quality assessment in Mediterranean wetlands based on crustacean and insect assemblages: the case of Catalunya (NE Iberian peninsula). Aquatic conservation: marine and freshwater ecosystems 15: 635-651.

Céréghino, R., J. Biggs, S. Declerck \& B. Oertli, 2008. The ecology of European ponds: defining the characteristics of a neglected freshwater habitat. Hydrobiologia 597: 1-6.

Chovanec, A., J. Waringer, M. Straif, W. Graf, W. Reckendorfer, A. Waringer-Löschenkohl, H. Waidbacher \& H. Schultz, 2005. The floodplain index-a new approach for assessing the ecological status of river/floodplain-systems according to the EU Water Framework Directive. Large Rivers 15: 169-185.

De Meester, L., S. Declerck, R. Stoks, G. Louette, F. Van de Meutter, T. De Bie, E. Michels \& L. Brendonck, 2005. Ponds and pools as model systems in conservation biology, ecology and evolutionary biology. Aquatic Conservation: Marine and Freshwater Ecosystems 15: 715-725.

Della Bella, V. \& L. Mancini, 2009. Freshwater diatom and macroinvertebrate diversity of coastal permanent ponds along a gradient of human impact in a Mediterranean ecoregion. Hydrobiologia (this issue).

Dimitriou, E., E. Moussoulis, F. Stamati \& N. Nikolaidis, 2009. Modeling hydrological characteristics of Mediterranean Temporary Ponds and potential impacts from climate change. Hydrobiologia (this issue).

Downing, J. A., J. J. Cole, J. J. Middelburg, R. G. Striegl, C. M. Duarte, P. Kortelainen, Y. T. Prairie \& K. A. Laube, 2008. Sediment organic carbon burial in agriculturally eutrophic impoundments over the last century. Global Biogeochemical Cycles 22: GB1018.

Downing, J. A., Y. T. Prairie, J. J. Cole, C. M. Duarte, L. J. Tranvik, R. G. Striegl, W. H. McDowell, P. Kortelainen, N. F. Caraco, J. M. Melack \& J. J. Middelburg, 2006. The global abundance and size distribution of lakes, ponds, and impoundments. Limnology and Oceanography 51: 2388-2397.

EPCN (European Pond Conservation Network), 2007. Developing the pond manifesto. Annales de LimnologieInternational Journal of Limnology 43: 221-232.

EPCN (European Pond Conservation Network), 2008. The Pond Manifesto: $20 \mathrm{pp}$.

Fahd, K., A. Arechederra, M. Florencio, D. León \& L. Serrano, 2009. Copepods and Branchiopods of temporary ponds in the Doñana Natural Area (SW Spain): a four-decade record (1964-2007). Hydrobiologia (this issue).

Florencio, M., L. Serrano, C. Gómez-Rodríguez, A. Millán \& C. Díaz-Paniagua, 2009. Inter and intra-annual variations of macroinvertebrate assemblages are related to the hydroperiod in Mediterranean temporary ponds. Hydrobiologia (this issue).

Indermuehle, N., S. Angélibert, V. Rosset \& B. Oertli, 2009. The pond biodiversity index "IBEM": a new tool for the rapid assessment of biodiversity in ponds from Switzerland. Part 2. Method description and examples of application. Limnetica (in press).

Oertli, B., D. Auderset Joye, E. Castella, R. Juge, D. Cambin \& J.-B. Lachavanne, 2002. Does size matter? The relationship between pond area and biodiversity. Biological Conservation 104: 59-70.

Oertli, B., D. Auderset Joye, E. Castella, R. Juge, A. Lehmann \& J.-B. Lachavanne, 2005a. PLOCH: a standardized method for sampling and assessing the biodiversity in ponds. Aquatic Conservation: Marine and Freshwater Ecosystems 15: 665-679.

Oertli, B., J. Biggs, R. Céréghino, P. Grillas, P. Joly \& J.-B. Lachavanne, 2005b. Conservation and monitoring of pond biodiversity: introduction. Aquatic Conservation: Marine and Freshwater Ecosystems 15: 535-540.

Peretyatko, A., S. Teissier, S. De Backer \& L. Triest, 2009. Restoration potential of biomanipulation for eutrophic peri-urban ponds: the role of zooplankton size and submerged macrophyte cover. Hydrobiologia (this issue).

Pinto-Cruz, C., J. A. Molina, M. Barbour, V. Silva \& M. D. Espírito-Santo, 2009. Plant communities as a tool in temporary ponds conservation in SW Portugal. Hydrobiologia (this issue).

Rannap, R., A. Lõhmus \& L. Briggs, 2009. Restoring ponds for amphibians: a success story. Hydrobiologia (this issue).

Rhazi, L., P. Grillas, M. Rhazi \& J.-C. Aznar, 2009a. 10-years dynamics of vegetation in relation with fluctuating hydrology in a Mediterranean temporary pool (Western Morocco). Hydrobiologia (this issue).

Rhazi, M., P. Grillas, L. Rhazi, A. Charpentier \& F. Médail, 2009b. Competition in microcosm between a clonal plant species (Bolboschoenus maritimus) and a rare quillwort (Isoetes setacea) from Mediterranean temporary pools of southern France. Hydrobiologia (this issue).

Ricciardi, A., 2006. Are modern biological invasions an unprecendent form of global change? Conservation Biology 21: 329-336.

Robinson, C. T. \& B. Oertli, 2009. Long-term biomonitoring of alpine waters in the Swiss National Park. eco.mont 1: 23-34.

Rodríguez-Pérez, H., M. Florencio, C. Gómez-Rodríguez, A. J. Green, C. Díaz-Paniagua, L. Serrano, 2009. Monitoring the invasion of the aquatic bug Trichocorixa verticalis verticalis (Hemiptera: Corixidae) in the wetlands of Doñana National Park (SW Spain). Hydrobiologia (this issue).

Rosset, V., B. Oertli, S. Angélibert \& N. Indermuehle, 2008. The local diversity of macroinvertebrates in alpine ponds as an indicator of global changes: a Gastropod case-study. Verhandlungen Internationale Vereinigung Limnologie 30: 482-484.

Ruhí, A., D. Boix, J. Sala, S. Gascón \& X. D. Quintana, 2009. Spatial and temporal patterns of pioneer macrofauna in recently created ponds: taxonomic and functional approaches. Hydrobiologia (this issue).

Sager, L. \& J.-B. Lachavanne, 2009. The M-TIP: a macrophyte based trophic index for ponds. Hydrobiologia (this issue).

Sahib, N., L. Rhazi, M. Rhazi \& P. Grillas, 2009. Experimental study of the effect of hydrology and mechanical soil disturbance on plant communities in Mediterranean temporary pools in Western Morocco. Hydrobiologia (this issue).

Santoul, F., A. Gaujard, S. Angélibert, S. Mastrorillo \& R. Céréghino, 2009. Gravel pits support waterbird diversity in an urban landscape. Hydrobiologia (this issue). 
Scher, O., P. Chavaren, M. Despreaux \& A. Thiéry, 2004. Highway stormwater detention ponds as biodiversity islands? Archives des Sciences 57: 121-130.

Solimini, A., M. Bazzanti, A. Ruggiero \& G. Carchini, 2008. Developing a multimetric index of ecological integrity based on macroinvertebrates of mountain ponds in central Italy. Hydrobiologia 597: 109-123.

Triest, L. \& T. Sierens, 2009. High diversity of Ruppia meadows in saline ponds and lakes of the western Mediterranean. Hydrobiologia (this issue).

Trigal, C., F. García-Criado \& C. Fernández-Aláez, 2009. Towards a multimetric index for ecological assessment of
Mediterranean flatland ponds: the use of macroinvertebrates as bioindicators. Hydrobiologia 618: 109-123.

Williams, P., M. Whitfield \& J. Biggs, 2008. How can we make new ponds biodiverse? - a case study monitored over 8 years. Hydrobiologia 597: 137-148.

Williams, P., M. Whitfield, J. Biggs, S. Bray, G. Fox, P. Nicolet \& D. Sear, 2003. Comparative biodiversity of rivers, streams, ditches and ponds in an agricultural landscape in Southern England. Biological Conservation 115: 329-341. 